\title{
Influence of encapsulated sunflower oil on the mechanical and self-healing properties of dense-graded asphalt mixtures
}

\author{
Jose Norambuena-Contreras • Quantao Liu • Lei Zhang • Shaopeng Wu • \\ Erkut Yalcin $\cdot$ Alvaro Garcia $(\mathbb{B}$
}

Received: 30 November 2018/ Accepted: 23 June 2019/Published online: 6 July 2019

(C) The Author(s) 2019

\begin{abstract}
This paper re-evaluates the effect of sunflower oil capsules on the mechanical and selfhealing properties of dense-graded asphalt mixtures. Different percentages of capsules $(0.50 \mathrm{wt} \%$, $0.75 \mathrm{wt} \%$ and $1.00 \mathrm{wt} \%$ ) were mixed into dense asphalt. The influence of capsules on the properties of asphalt such as density, indirect tensile strength, particle loss, fatigue life, and self-healing, has been investigated. The distribution and integrity of the capsules has been also evaluated by means of CT Scans. It has been proven that capsules can survive the mixing and compaction process of asphalt mixture, do not decrease its mechanical properties and they rupture and release the oil under a high compression loading. Higher capsule content in the mixture resulted
\end{abstract}

J. Norambuena-Contreras · E. Yalcin · A. Garcia $(\bowtie)$ Nottingham Transportation Engineering Centre, Faculty of Engineering, School of Civil Engineering, University of Nottingham, University Park, Nottingham, UK e-mail: alvaro.garcia@nottingham.ac.uk

J. Norambuena-Contreras

LabMAT, Department of Civil and Environmental

Engineering, University of Bío-Bío, Concepción, Chile

Q. Liu · L. Zhang · S. Wu

State Key Laboratory of Silicate Materials for Architectures, Wuhan University of Technology, Luoshi Road 122, Wuhan 430070, China

E. Yalcin

Department of Civil Engineering, Faculty of Engineering, Firat University, Elazig, Turkey in higher oil release ratios. Furthermore, the oil released from the capsules significantly increased the self-healing capability of mixtures. Results from previous research were validated, where it had been found that $0.5 \%$ of capsules is the optimal content to obtain good mechanical performance, without affecting the rheological properties of dense-graded asphalt mixtures.

Keywords Dense asphalt mixture - Encapsulated rejuvenators $\cdot$ Mechanical properties $\cdot$ Self-healing capability

\section{Introduction}

In the most parts of the world, asphalt mixture is the preferred surface material to build highway and urban roads due to its low roughness and economy. Nevertheless, cracking due to changes of temperature, moisture, and repeated loads may severely reduce the service life of asphalt pavements [1]. Asphalt is the mixture of aggregates, which give structural strength to the material, and bitumen, a liquid that holds the aggregates together and which viscosity is temperature-dependant. Asphalt mixture is a self-healing material, because bitumen has the capacity to flow and drain into the cracks [2]. Asphalt pavements can autonomously repair their internal cracks if the 
conditions are appropriate, such as aggregate gradation, and bitumen's or mastic's viscosity, [3, 4]. Nevertheless, the bitumen tends to age and its viscosity to increase during the mixing, compaction and service life, which reduces the self-healing capability of asphalt mixture and hence, reduces its lifespan [5].

To improve the self-healing properties of asphalt roads and extend their lifespan, researchers have developed two technologies that improve the drainage of bitumen into the cracks. The first technology involved mixing metallic additives into the asphalt mixture and heating them by means of an electromagnetic field such as induction or microwave radiation [6], to make bitumen expand and push it into the cracks [7]. The second technology was the addition of encapsulated oil into the asphalt mixture [8]. When the capsules were ruptured due to traffic loading, the oil was released and diffused into the mixture. Therefore, the viscosity of bitumen around the capsule reduced while the concentration of oil was still high, and bitumen could drain more easily into the cracks [9]. This paper will focus on the use of capsules to improve the healing properties of asphalt roads.

There are different types of capsules that have been previously developed, representative examples, albeit not the only ones, are those developed by Su et al. [10], which are micron-sized with core-shell structure, and those developed by Garcia et al. [11], which are millimetre-sized, with a porous internal structure. It has been proven that encapsulated oil can survive mixing and compaction of asphalt mixture, and improve its self-healing properties [12]. In addition, Tabaković et al. [13], have developed hollow fibres that contain healing agents agent rather than capsules, although these fibres are still in a premature phase of their development.

In this paper, we will focus on the capsules developed by Micaelo et al. [14] and Al-Mansoori et al. [15-17] for asphalt self-healing (ca-alginate capsules). They are composed of a membrane of calcium-alginate capsules that contains sunflower oil and protects it from the environment. Similar capsules were also manufactured by Norambuena-Contreras et al. [18] and Xu et al. [19] for self-healing of asphalt mastic, dense asphalt mixture and Stone Mastic Asphalt [20]. In these works it was proven that the capsules had a positive effect on the compatibility, particle loss and self-healing properties of the mixture, whereas an adverse effect on stiffness modulus when the content of capsules substantially increased [16-19] and, the reason for this is probably the low strength of the capsules; they should have been made stronger. If the content of capsules is too low, their effect on the self-healing properties of asphalt will be limited. If an excess of capsules is added to the asphalt pavement, the stiffness and rutting resistance may be reduced because if strength has not been correctly designed [15].

This paper aims to re-evaluate and summarise the effect of the addition of the capsules developed in Ref. [15] on the durability, including fatigue performance and self-healing, of dense-graded asphalt mixtures. To achieve this goal, three percentages of capsules, $0.50 \%, 0.75 \%$ and $1.00 \%$, have been added to dense asphalt mixture. Properties such as indirect tensile strength, particle loss and fatigue life of the mixtures with capsules were investigated. Moreover, the influence of different percentages of capsules on the selfhealing of the asphalt mixture was examined. Finally, $\mathrm{X}$-ray computed tomography tests were carried out to evaluate the distribution and integrity of the capsules in the mixture. The experimental design can be seen in Fig. 1.

\section{Materials and test methods}

\subsection{Raw materials}

The asphalt mixture used in this research was a standard dense asphalt mixture AC-13, whose gradation is shown in Table 1. Basalt gravel with density $2.976 \mathrm{~g} / \mathrm{cm}^{3}$, limestone filler with density $2.669 \mathrm{~g} /$ $\mathrm{cm}^{3}$, and unmodified bitumen with penetration 77.5 $(0.1 \mathrm{~mm})$ and softening point $49.1{ }^{\circ} \mathrm{C}$ were used to prepare the mixture. Moreover, $\mathrm{Ca}$-alginate capsules with a density of $1.116 \mathrm{~g} / \mathrm{cm}^{3}$ were prepared. The rejuvenating agent used was sunflower oil with a density of $0.92 \mathrm{~g} / \mathrm{cm}^{3}$, smoke point $227{ }^{\circ} \mathrm{C}$ and flash point $315{ }^{\circ} \mathrm{C}$ [14]. The polymeric structure of the capsules was made of sodium alginate $\left(\mathrm{C}_{6} \mathrm{H}_{7} \mathrm{O}_{6} \mathrm{Na}\right)$ and calcium chloride $\left(\mathrm{CaCl}_{2}\right)$ provided in granular pellets with $93 \%$ purity. The main thermal and mechanical properties of the used calcium-alginate capsules can be consulted in [18]. 


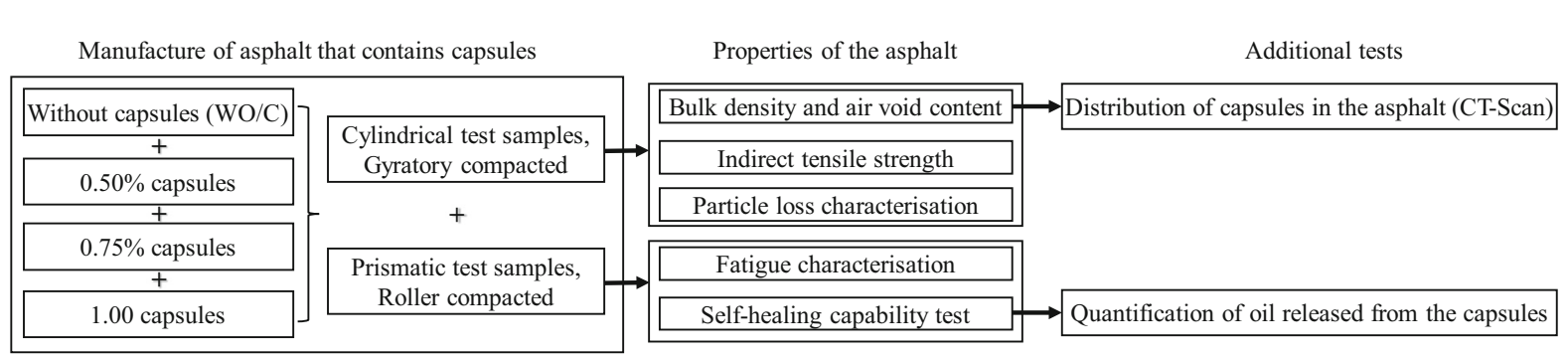

Fig. 1 Experimental design of the study

Table 1 Gradation of the AC-13 asphalt mixture

\begin{tabular}{lc}
\hline Sieve size $(\mathrm{mm})$ & Passing $(\%)$ \\
\hline 16 & 100.0 \\
13.2 & 96.2 \\
9.5 & 75.2 \\
4.75 & 47.4 \\
2.36 & 30.8 \\
1.18 & 23.9 \\
0.6 & 16.6 \\
0.3 & 12.3 \\
0.15 & 9.1 \\
0.075 & 6.9 \\
\hline
\end{tabular}

\subsection{Preparation of the Ca-alginate capsules}

The encapsulation procedure is shown in Fig. 2 and step-by-step described in Al-Mansoori et al. [16]. Caalginate capsules were prepared at $20{ }^{\circ} \mathrm{C}$ by ionotropic

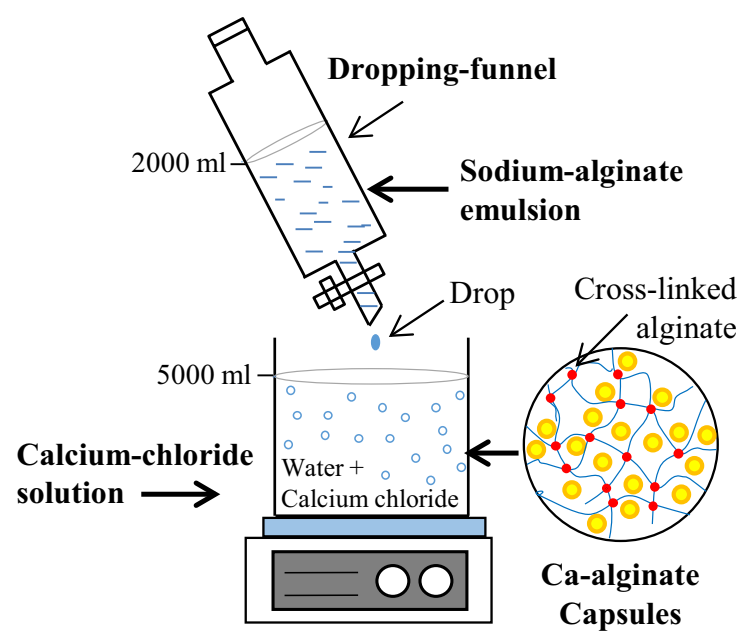

Fig. 2 Scheme of the encapsulation procedure by ionotropic gelation gelation of sodium alginate in the presence of calcium ions [14-16]. The capsule preparation method consisted of the following three steps: (1) preparation of the sodium-alginate emulsion; (2) preparation of the calcium-chloride solution and capsule synthesis; and (3) drying and storing of the capsules. Capsules were prepared in a relationship 1:3 at vol of rejuvenator and Ca-alginate polymer, respectively. Figure 3 a shows an optical image of the capsules with a size $2.5 \mathrm{~mm}$. Figure $3 b$ shows a SEM image of the cross-section of an individual capsule composed of a multi-cavity structure. A total of $2.5 \mathrm{~kg}$ of capsules were manufactured in this work.

\subsection{Manufacturing of asphalt mixture samples}

Asphalt mixture test specimens with, and without, $\mathrm{Ca}-$ alginate capsules were manufactured using $4.7 \%$ of binder content. In the mixtures with capsules, three different capsule contents as a percentage of the total mixture mass were used: $0.5 \%, 0.75 \%$ and $1.0 \%$, thus providing an oil-to-bitumen content by mass in bitumen of approximately $6.97 \%, 10.46 \%$ and $13.95 \%$, respectively. Due to the low content (no more than $1.00 \%$ ), capsules were added directly to the asphalt mixture without changing the aggregate gradation.

The cylindrical samples used for mechanical tests were manufactured according to the following procedure: (1) the aggregates and bitumen were pre-heated at $160{ }^{\circ} \mathrm{C}$ for $12 \mathrm{~h}$ and $4 \mathrm{~h}$, respectively; (2) the asphalt mixture components were mixed with the laboratory mixer at $160{ }^{\circ} \mathrm{C}$; (3) the capsules, at $20{ }^{\circ} \mathrm{C}$, were added to the mixture and mixed for $15 \mathrm{~s}$; (4) the asphalt mixtures containing capsules were poured into a mould and compacted using the rutting plate moulding machine; (5) asphalt test cylinders $(\Phi 100 \mathrm{~mm} \times 50 \mathrm{~mm})$ were drilled from each plate 

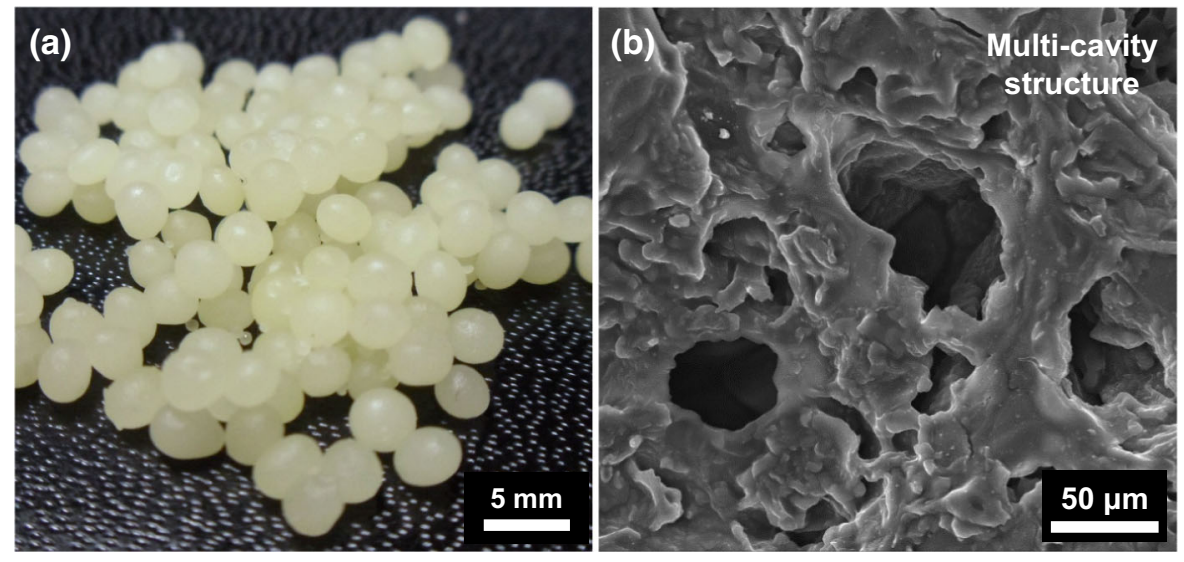

Fig. 3 a Optical image of Ca-alginate capsules, and b SEM image of the cross-section of an individual capsule

using a pavement coring machine. Additionally, cylindrical cores $(\Phi 35 \mathrm{~mm} \times 50 \mathrm{~mm})$ were drilled from the cylinders for CT-Scan characterisation.

Furthermore, asphalt mixture slabs were manufactured using the rutting plate moulding machine, and prismatic samples were cut for the crack-healing measurements. Asphalt mixtures were manufactured in batches of $14 \mathrm{~kg}$ using a laboratory mixer with a total capacity of $25 \mathrm{~kg}$. After mixing, mixtures were transferred to the steel moulds for their compaction and sawing as follows: asphalt slabs of $306 \times 306 \times 60 \mathrm{~mm}^{3}$ were compacted using a roller compactor to reach air voids content $5 \%$. Then, prisms with dimensions $150 \times 100 \times 60 \mathrm{~mm}^{3}$ were sawed from a selection of slabs, and a transverse notch with dimensions $5 \times 5 \mathrm{~mm}^{2}$ was made at the mid-point of the beams to facilitate the start of a located single crack surface during crack-healing tests.

\subsection{Bulk density and air void content}

The bulk density and air void content play important roles in the mechanical properties of asphalt mixtures, including their fatigue life [18]. The maximum density of test specimens was determined through the BS EN 12697-5 [21] by the mathematical method. In addition, the bulk densities of the specimens with, and without, capsules were determined through the BS EN 12697-6 [22] by measuring the bulk density-saturated surface dry. Besides, the air void content of each test specimen was calculated based on the previous calculation of the maximum and bulk densities, as follows:
$\operatorname{AV}_{i}(\%)=\left(\frac{\rho_{\max }-\rho_{i}}{\rho_{\max }}\right) \times 100$

where $\mathrm{AV}_{i}$ is the air void content of each asphalt test specimen in $\%, \rho_{\max }$ is the theoretical maximum density without voids in $\mathrm{g} / \mathrm{cm}^{3}$, and $\rho_{i}$ is the bulk density of each test specimen in $\mathrm{g} / \mathrm{cm}^{3}$.

\subsection{Indirect tensile strength}

Indirect tensile strength (ITS) is an indicator of the cohesion between binder and aggregates or Ca-alginate capsules. Indirect tensile tests were used to characterise the effect of the capsule content on the mechanical properties of mixtures, compared with mixtures without capsules. Cylindrical test specimens were incubated at $25{ }^{\circ} \mathrm{C}$ for $4 \mathrm{~h}$ before the experiment. The load was applied at a rate of $50 \mathrm{~mm} / \mathrm{min}$ until the peak load was reached. ITS of the specimens was calculated as follows:

$\mathrm{ITS}=\frac{2 F}{\pi D H}$

where ITS is the indirect tensile strength in MPa; $F$ is the peak load in $N ; D$ is the diameter of the cylinder in $\mathrm{mm} ; H$ is the thickness of the cylindrical specimen in $\mathrm{mm}$.

\subsection{Particle loss tests}

The authors understand that the Ca-alginate capsules may reduce the adhesion between the aggregates and the mixture, causing increased roughness. For this reason, the particle loss (ravelling) resistance of 
asphalt mixtures with, and without, capsules was evaluated through particle loss tests. Test specimens were placed into a water bath at $20{ }^{\circ} \mathrm{C}$ for $20 \mathrm{~h}$ and then put into a Los Angeles abrasion machine without steel balls. The drum was rotated at a speed of $30 \mathrm{rpm}$ for 300 revolutions. The result was calculated by comparing the mass of the specimens before, and after, being tested.

$\mathrm{PL}(\%)=\left(\frac{\mathrm{W}_{i 1}-\mathrm{W}_{i 2}}{\mathrm{~W}_{i 1}}\right) \times 100$

where PL is particle loss of each test specimen in \%; $\mathrm{W}_{i 1}$ is the initial mass of the sample in $\mathrm{g}$; $\mathrm{W}_{i 2}$ is the residual mass of the test specimen in $\mathrm{g}$.

\subsection{Fatigue characterisation}

Fatigue characterisation of asphalt mixtures with, and without, different contents of capsules was studied using indirect tensile fatigue tests at a wide range of forces, adapted from Ref. [23]. A Universal Testing Machine UTM-25 was used to apply half-sine repeated loads until the cumulative amount of displacement led to the test specimen fracture. The test frequency was $1 \mathrm{~Hz}$. In each loading cycle, the loading time was $0.1 \mathrm{~s}$ and the intermittent time was $0.9 \mathrm{~s}$. This experiment was performed at a standard test temperature of $15{ }^{\circ} \mathrm{C}$. The fatigue lives obtained under different stress levels were analysed by the following regression equation:

$N_{\mathrm{f}}=K\left(\frac{1}{\sigma_{0}}\right)^{n}$

where $N_{\mathrm{f}}$ is the number of fatigue cycles when the test specimen breaks; $\sigma_{0}$ is the horizontal tensile stress at the specimen center in MPa, and $K$ and $n$ are fatigue regression constants.

\subsection{Self-healing capability tests}

The influence of capsule addition on the self-healing capability of mixtures was evaluated using the mechanical crack-healing test previously developed by Al-Mansoori et al. [15-17]. The prisms where frozen at $-20{ }^{\circ} \mathrm{C}$ and tested under three-point bending. After, the two halves of the beams were placed together, in a steel mould, with a thin plastic sheet in the crack, to avoid the contact between both faces. A confined static compressive load of $75 \mathrm{kN}$ was applied on the surface of asphalt prisms to simulate traffic loading and break the capsules. The pressure value used in the test is the same as that used by the Mobile Load Simulators (such as MLS30) for simulating a large-scale accelerated damage on the asphalt pavements with self-healing purposes [24]. Finally, once the capsules had been damaged, the plastic sheet was removed, the prism halves placed together, and the prisms rested at $20{ }^{\circ} \mathrm{C}$. The step-bystep test procedure has been described in Norambuena-Contreras et al. [18]. Figure 4 shows a schematic description of the test procedure.

Crack-healing performance of asphalt beams with, and without, capsules was quantified as the healing level reached from the three-point bending strength recovery of cracked beams tested under a three-point bending test after a defined healing time. Ten different healing times (i.e. 5, 24, 48, 72, 96, 120, 144, 168, 192 and $216 \mathrm{~h}$ ) were tested. The healing level reached by each beam after a specific healing time was defined as follows:

$\mathrm{HL}(\%)=\left(\frac{F_{i \text {-healed }}}{F_{i-\text { initial }}}\right) \times 100$

where $\mathrm{HL}$ is the healing level defined as the relationship between the maximum force of the beam initially tested, $F_{\text {initial }}$, and the maximum force measured in the same asphalt beam after the healing process, $F_{\text {healed}}$.

\subsection{Quantification of oil released level by the capsules}

The level of oil released by the Ca-alginate capsules into the asphalt was chemically quantified by means of Fourier-Transform Infrared Spectroscopy (FTIR) tests according to Micaelo et al. [14] and NorambuenaContreras et al. [18].

FTIR tests, were carried out on two sample groups as follows: (1) As a reference, test samples of virgin bitumen with the same amount of rejuvenator contained in the different percentages of capsules (i.e., simulating $100 \%$ of oil released from $0.5 \%, 0.75 \%$ and $1.0 \%$ of capsules added to the mixture). (2) Test samples were randomly extracted, using a hot knife, from beams that had been made with and without capsules before, and after, healing tests. The results 

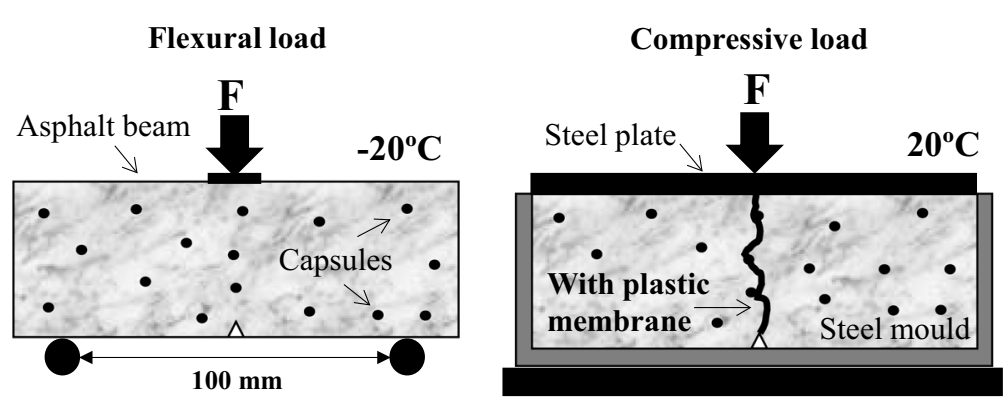

Healing time: 5-216 h

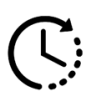

Step 1: Crack generation

Step 2: Capsules activation

Step 3: Healing process

\section{Repeat Step 1}

Fig. 4 Schematic diagram of the crack self-healing test on the asphalt slabs (modified from [20])

were compared to those of the reference, to know the percentage of oil in the capsules.

FTIR analysis was developed using a spectrum device, set in the absorption mode in the wavenumber range of 400 to $4000 \mathrm{~cm}^{-1}$ at a resolution of $4 \mathrm{~cm}^{-1}$. The absorbance spectrum in FTIR curves was normalised, and the absorbance area under the spectrum was measured [25]. Figure 5 shows an example of the curves obtained from asphalt samples containing $0.5 \%$ of Ca-alginate capsules, where the oil releasing effect on the bitumen was evaluated from changes in the absorbance peak between the wavenumbers 1700 to $1800 \mathrm{~cm}^{-1}$ [17]. Using the absorbance area results, the Oil Released Level, ORL, from the capsules into the asphalt beams before, and after, crack-healing tests was defined as follows:

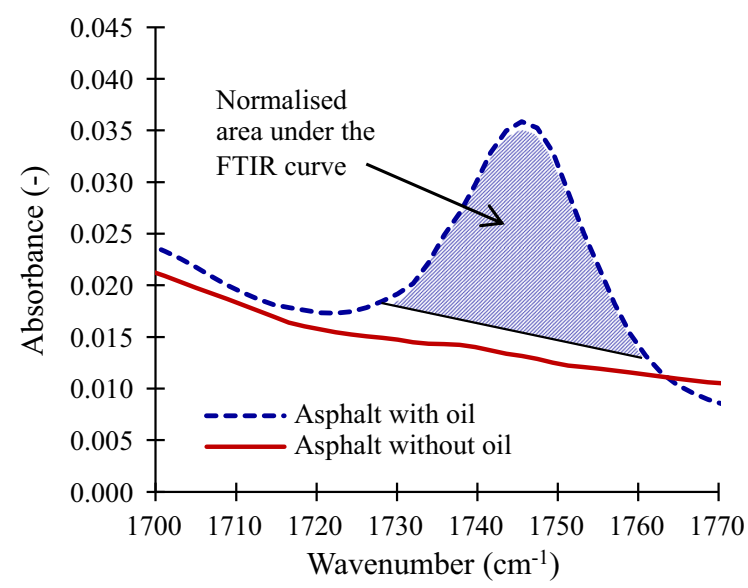

Fig. 5 Example of FTIR curves of asphalt samples without, and with, oil $(0.5 \%$ of capsules)
$\operatorname{ORL}(\%)=\left(\frac{A_{1745-\mathrm{Si}}}{A_{1745-\mathrm{Ref}}}\right) \times 100$

where $A_{1745-\mathrm{Si}}$ is the absorbance area at the peak $1745 \mathrm{~cm}^{-1}$ for the specific asphalt sample containing different percentages of $\mathrm{Ca}$-alginate capsules (i.e. $0.5 \%, 0.75 \%$ and $1.0 \%$ ), and $A_{1745-\text { Ref }}$ is the absorbance area at the peak $1745 \mathrm{~cm}^{-1}$ for the asphalt sample with the $100 \%$ of oil released in asphalt, depending on the percentage of capsules added to the mixture.

\subsection{CT-Scan characterisation of the samples with capsules}

The distribution of the capsules and their structural integrity inside asphalt cores were evaluated by means of CT-Scan analysis following the procedure described in [18] and based on the following steps: (1) Several CT-Scan tests on cores were developed using a GE Sensing and Inspection Technologies GMBH Phoenix VTomeX M operated at $200 \mathrm{kV}$ and $180 \mu \mathrm{A}$; (2) The reconstruction and corrections of scans were performed using the Phoenix Datos X2 Reconstruction software; (3) Once reconstructed into $3 \mathrm{D}$ volumes, $2 \mathrm{D}$ image slices were exported in TIFF format along the XY axis.

\section{Het}




\section{Results and discussion}

\subsection{Effect of capsule addition on the density and air void content of dense asphalt}

Table 2 shows the average bulk density and air void content of asphalt mixtures with, and without, Caalginate capsules. Average values were calculated from 5 tested specimens for each capsule content in the mixture. In Table 2 it can be seen that the addition of capsules slightly decreased the density of the asphalt mixture. The reason for this reduction is that the density of the capsules $\left(1.116 \mathrm{~g} / \mathrm{cm}^{3}\right.$ at $\left.20{ }^{\circ} \mathrm{C}[18]\right)$ is lower than that of the aggregates and mastic in the mixture. However, the addition of $0.5 \%$ may contribute to reduce the air void content of the mixture, as it has been reported before by Al-Mansoori et al. [14].

\subsection{Distribution of capsules in the asphalt}

Figure 6 shows the results of X-ray computed tomography tests developed on asphalt cores with capsules. The capsules can resist the manufacturing process and mainly keep their oil content until they break due to the effect of external loading. Figure 6a shows that samples with $0.5 \%$ of capsules presented a good spatial distribution inside the mixture with minor percentage of broken capsules because of the manufacturing process, while mixtures with higher contents of capsules showed some clusters of capsules, see Fig. 6b. The reason for the cluster of the image is not clear and more research could be used in this direction; although it could have happened because the capsules were already clustered before mixing due to a poor curing of the alginate. The dispersion of similar capsules had been previously quantified in Ref. [14] and did not show any remarkable results.

Furthermore, CT-Scan images shown in Fig. 6c, d showed that the capsules used in this study can resist mixing and compaction, and that they get damaged by the interaction with the aggregates. In previous studies $[18,20]$ the authors observed the microstructure of the capsules by scanning electron microscope (SEM) images, concluding that the structure of the designed capsules is a porous microbead, see Fig. 3b. It is not yet clear how the oil is released from the capsules and must be part of a more extensive study but, the authors propose that this happens because the capsules simply get squeezed by the aggregates around them (see Fig. 9c). If this is true, capsules in porous asphalt may release the oil faster than capsules in denser mixtures. As the capsules present a multi-core structure, when one of the pockets of oil is broken by the pressure of the aggregates during the cyclic loading of the asphalt, the rest of the oil's pocket may still remain intact, although this is a topic for future research.

\subsection{Effect of capsules on the indirect tensile strength (ITS) of asphalt mixture}

Figure 7 shows the ITS results of asphalt samples without and with capsules. Average values were calculated from 3 tested specimens for each capsule content in the mixture. It is shown in Fig. 7a that asphalt mixtures with $0.5 \%$ of capsules are stiffer than asphalt mixtures without capsules, as well as mixtures with $0.75 \%$ and $1.00 \%$ of capsules. Figure $7 \mathrm{~b}$ shows the average maximum ITS values registered at a displacement of $3.05 \mathrm{~mm}$. It shows that asphalt mixture with $0.5 \%$ of capsules has higher average ITS than asphalt mixture without capsules, or with $0.75 \%$ and $1.00 \%$ of capsules. The reason can be attributed to the lower air void content of the asphalt mixture containing $0.5 \%$ of capsules. When more $\mathrm{Ca}-$ alginate capsules were added to the mixture, the air void content of the mixture increased (see Table 2), and more oil was released from the capsules, decreasing the stiffness and ITS of the asphalt mixtures.

Table 2 Density and air void content of asphalt mixture with, and without (WO/C), capsules

\begin{tabular}{llll}
\hline Type of mixture & Bulk density $\left(\mathrm{g} / \mathrm{cm}^{3}\right)$ & Theoretical maximum density $\left(\mathrm{g} / \mathrm{cm}^{3}\right)$ & Air void content $(\%)$ \\
\hline WO/C & 2.559 & 2.679 & 4.5 \\
$0.5 \%$ caps & 2.557 & 2.669 & 4.2 \\
$0.75 \%$ caps & 2.529 & 2.668 & 5.2 \\
$1.00 \%$ caps & 2.499 & 2.664 & 6.2 \\
\hline
\end{tabular}



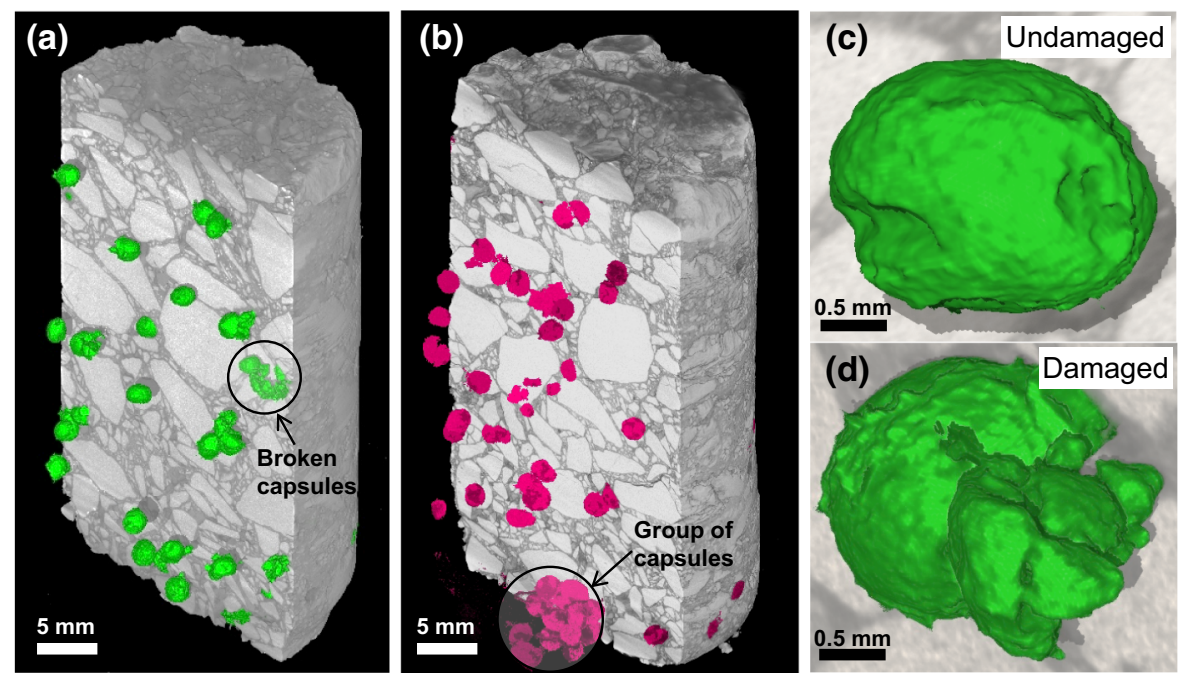

Fig. 6 CT-Scan reconstruction of the asphalt mixture cores containing a $0.5 \%$ (based on [18]) and b $0.75 \%$ of capsules, and two individual capsules from the mixture with $0.5 \%$ of capsules, one undamaged (c) and the other one damaged (d)
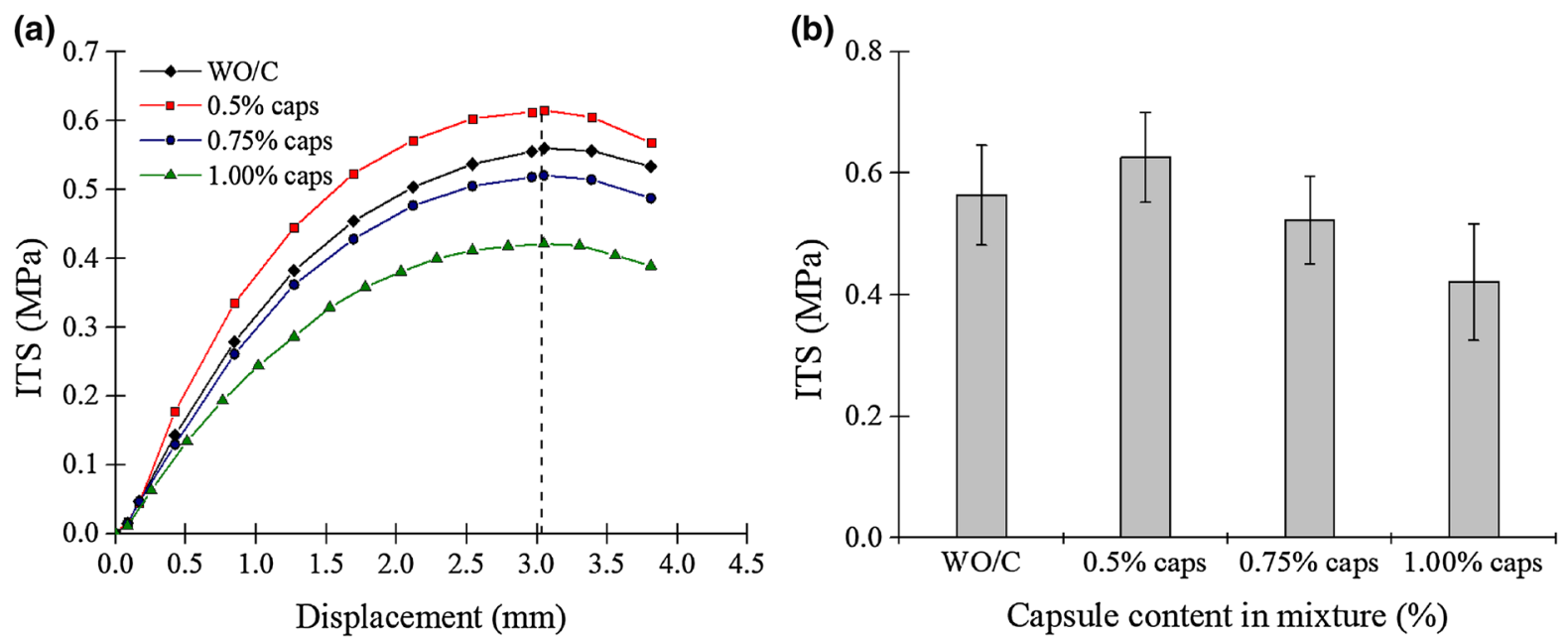

Fig. 7 a Average ITS curves and $\mathbf{b}$ maximum average ITS results for asphalt samples with, and without (WO/C), capsules

\subsection{Effect of capsules on the particle loss properties of asphalt mixture}

Figure 8 shows the particle loss percentage of asphalt samples with, and without, capsules. Average values were calculated from 5 tested specimens for each capsule content in the mixture. In Fig. 8 it can be seen that the average particle loss of the asphalt mixture without capsules and with $0.5 \%, 0.75 \%$ and $1.00 \%$ of capsules was $4.94 \%, 5.07 \%, 5.76 \%$ and $6.06 \%$, respectively. It means that the addition of $\mathrm{Ca}$-alginate capsules increases the particle loss of asphalt mixtures.
The mixture with $0.5 \%$ of capsules has almost the same average particle loss resistance than the mixture without capsules. As well, visual inspection of test specimens containing capsules showed that they can successfully resist the impacts during the particle loss test. Similar results have also been reported in 2017 by Al-Mansoori et al. [15]. 


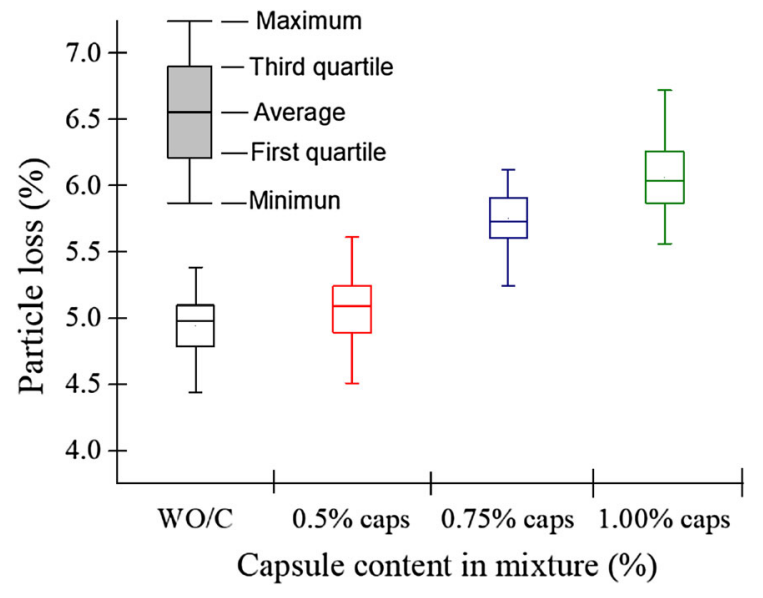

Fig. 8 Results of particle loss of asphalt samples with, and without (WO/C), capsules

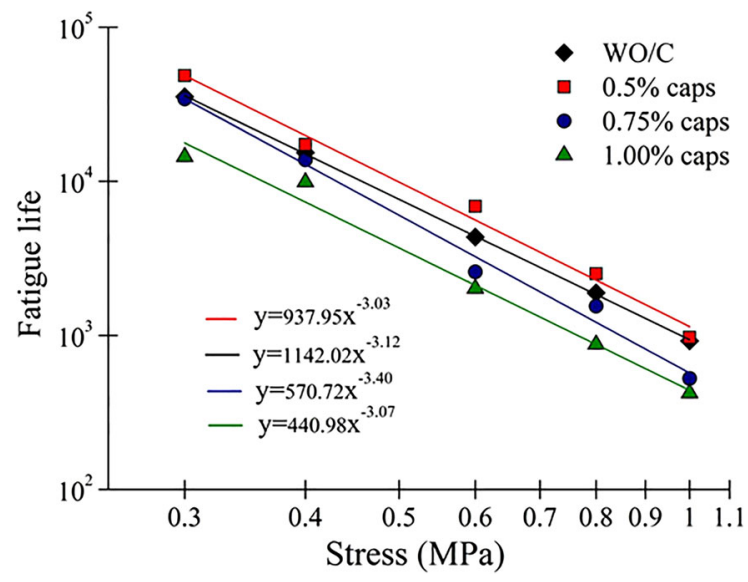

Fig. 9 Results of average fatigue tests of asphalt samples with, and without (WO/C), capsules

\subsection{Effect of capsules on the durability to of asphalt mixture}

Furthermore, Fig. 9 shows the fatigue properties of asphalt samples with and without capsules. Average values were calculated from 3 tested specimens for each capsule content in the mixture. In Fig. 9 the addition of $0.5 \%$ capsules improves the fatigue resistance of asphalt mixture at all stress levels. It can be attributed to the lower air voids content and higher strength of the mixture containing $0.5 \%$ of capsules, see ITS results in Fig. 7. The addition of more capsules (i.e. $0.75 \%$ and $1.00 \%$ of capsules) decreases the fatigue resistance of asphalt mixture. This can be attributed to that an excess of capsules increases the air voids of the mixture, as seen in Table 2.

\subsection{Influence of the capsule amount on the self-} healing capability of the mixtures

Figure 10a shows the healing levels reached by the asphalt samples with, and without, capsules, at different healing times. Each point in the graph represents one tested beam depending on the capsule content and healing time. The high number of tests done and good fitting of the results tell us abou the high quality of the data obtained. It can be seen that: (1) the healing levels achieved by the asphalt samples with capsules were higher than those reached by test beams without capsules, and (2) the healing level of asphalt beams with, and without, capsules increased with the healing time until a maximum value. It can be seen that the maximum healing level value was reached at a healing time of $96 \mathrm{~h}$ and remained mostly constant until $216 \mathrm{~h}$, see continuous healing range in Fig. 10a. Hence, the healing level reached by the beams between 96 and $216 \mathrm{~h}$ can be considered as the maximum healing level of the mixtures.

Consequently, the average maximum healing levels for asphalt mixtures without capsules and containing $0.5 \%, 0.75 \%$ and $1.00 \%$ of capsules were $20.44 \%$, $49.04 \%, 54.32 \%$ and $54.86 \%$, respectively. These results proved that higher capsule contents into the mixture resulted in higher healing levels for all the healing times studied, see Fig. 10a. This is because higher capsule contents increase the probability of breaking more capsules as a result of the external compression load applied during the test, which also increase the potential released oil inside the asphalt by mechanical effects [18].

The level of oil released in asphalt measured by FTIR tests after tests was $35.45 \%, 45.02 \%$ and $60.93 \%$ for Ca-alginate capsule contents of $0.5 \%, 0.75 \%$ and $1.00 \%$, respectively, see Fig. 10b. Nevertheless, this level of oil released in asphalt is not only related to the application of the external load, but also to the manufacturing process of the mixtures where the capsules can also be damaged. After the manufacturing process of the mixtures, low levels of oil released were quantified: $3.22 \%, 4.09 \%$ and $5.54 \%$ for capsule contents of $0.5 \%, 0.75 \%$ and $1.00 \%$, respectively.

Healing levels presented in Fig. 10a also show that capsule contents higher than $0.5 \%$ did not present a 
(a)

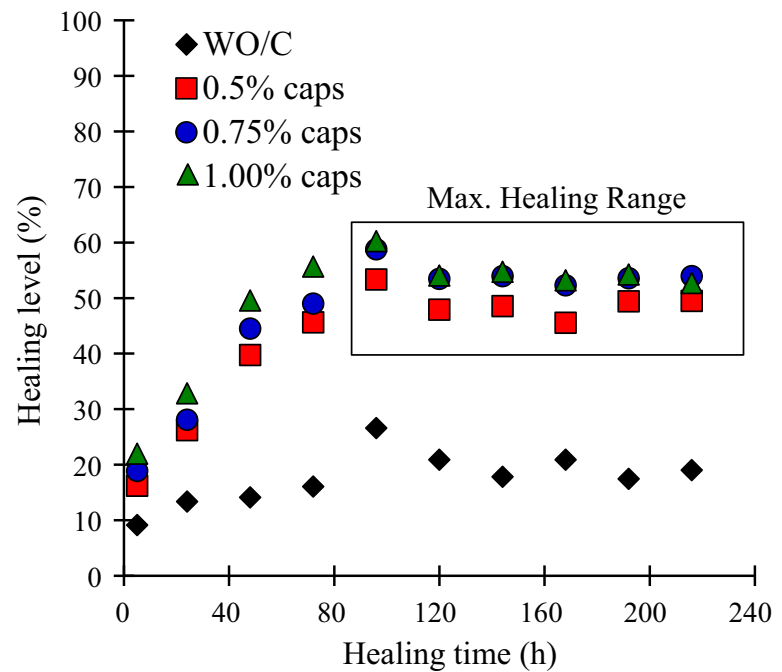

(b)

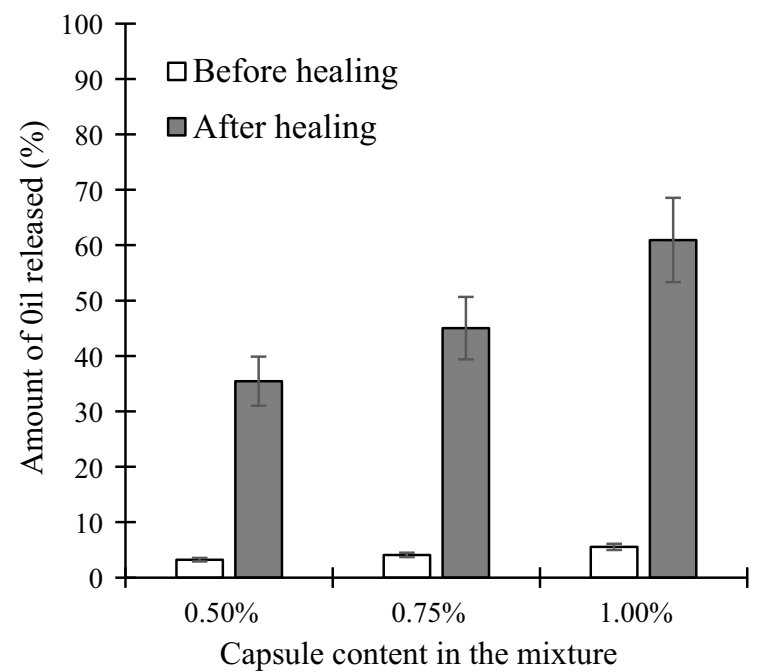

Fig. 10 Results of the: a crack-healing levels for the asphalt beams with, and without (WO/C), capsules depending on the healing time, and $\mathbf{b}$ percentage of oil released inside the different mixtures before, and after, healing process

significant increase in the maximum healing levels, see results of $0.75 \%$ and $1.00 \%$ in the maximum healing range. This result can be due to an excess of rejuvenating agent (i.e. oil-to-bitumen content) inside the asphalt mixture. In this study, oil-to-bitumen content by mass in bitumen was $6.97 \%, 10.46 \%$ and $13.95 \%$ for capsule contents of $0.5 \%, 0.75 \%$ and $1.00 \%$, respectively. Previous researches [26] developed on aged asphalt binders rejuvenated with vegetable oil, proved that contents over $7.0 \%$ by mass of bitumen, can be detrimental to the properties of the mixture, affecting the rheological properties of bitumen. Therefore, based on the results of this study, $0.5 \%$ of capsule addition can be considered as the optimal percentage for asphalt healing without affecting the rheological properties of the dense-graded asphalt mixture.

\subsection{Summary and discussion of results}

Table 3 provides a general overview of the effect of the Ca-alginate capsule addition on the density, air void content, indirect tensile strength, average loss resistance, fatigue performance, and healing properties of dense-graded asphalt mixture. In this Table, it can be seen that depending on the capsule content added to the mixture (i.e. $0.5 \%, 0.75 \%$ or $1.00 \%$ ) the effect of the capsules on the properties evaluated was different. The Ca-alginate capsules reduced the average bulk density of the mixture regardless of the amount of capsules added, which is logical because they had lower density than the aggregates; although the effect of adding $0.5 \%$ capsules on density was very low $(-0.1 \%$, see Table 3$)$ compared with mixtures containing a higher capsule content; this makes think the authors that this is an appropriate amount to mix in the asphalt. In [15] and [16] it was evidenced that Caalginate capsules adapt their shape to the aggregates because their composition and spherical shape make them flow better during manufacturing process, see also Fig. 6c. Capsule contents of $0.75 \%$ and $1.00 \%$ increased the average air void content of the mixture, while $0.5 \%$ of capsules reduced the air void in a $6.7 \%$ compared with the mixture without capsules.

Furthermore, capsule contents of $0.75 \%$ and $1.00 \%$ negatively affected the maximum indirect tensile strength (ITS), while a $0.5 \%$ of capsules increased the ITS in an $11 \%$ compared with the mixture without capsules. Conversely, capsule addition negatively affected the average particle loss resistance of the mixture. Nonetheless, the effect of adding 0.5\% capsules on particle loss resistance was low $(-2.5 \%$, see Table 3$)$ compared with the mixture with a higher capsule content. The reason for the increase in particle loss could be that capsules adapted their shape to the surrounding aggregates into the 
Table 3 Comparison of asphalt mixtures with capsules to mixtures without them (values in \%)

\begin{tabular}{llll}
\hline Property evaluated & \multicolumn{2}{l}{$\begin{array}{l}\text { Capsule content by total weight of the mixture } \\
\text { (Notation: } \boldsymbol{\nabla} \text { decrease and } \boldsymbol{\Delta} \text { increase) }\end{array}$} \\
\cline { 2 - 4 } & $0.50 \%$ & $0.75 \%$ & $1.00 \%$ \\
\hline Average bulk density & $\boldsymbol{\nabla}(-0.1)$ & $\boldsymbol{\nabla}(-1.2)$ & $\boldsymbol{\nabla}(-2.3)$ \\
Average air void content & $\boldsymbol{\nabla}(-6.7)$ & $\boldsymbol{\Delta}(15.6)$ & $\boldsymbol{\Delta}(37.8)$ \\
Maximum indirect tensile strength & $\boldsymbol{\Delta}(11.0)$ & $\boldsymbol{\nabla}(-7.3)$ & $\boldsymbol{\nabla}(-25.4)$ \\
Average particle loss resistance & $\boldsymbol{\nabla}(-2.5)$ & $\boldsymbol{\nabla}(-16.5)$ & $\boldsymbol{\nabla}(-22.7)$ \\
Average fatigue life & $\mathbf{\Delta}(29.3)$ & $\boldsymbol{\nabla}(-23.0)$ & $\boldsymbol{\nabla}(-51.3)$ \\
Maximum healing level (at $96 \mathrm{~h})$ & $\mathbf{\Delta}(100.9)$ & $\boldsymbol{\Delta}(121.3)$ & $\boldsymbol{\Delta}(126.8)$
\end{tabular}

asphalt matrix, modifying the density of the material and consequently increasing the air void content in the mixture.

Furthermore, it was observed that capsule contents of $0.75 \%$ and $1.00 \%$ negatively affected the average fatigue life, while a $0.5 \%$ of capsules increased the average fatigue life in a $29.3 \%$ compared with the mixture without capsules. Based on previous studies of the authors [15-18], the negative effect of the addition of $0.75 \%$ and $1.00 \%$ of capsules on the mechanical properties of the asphalt mixtures could have been magnified by the size of the capsules because they are part of the solid skeleton and they act as soft aggregates into the bituminous matrix, see Fig. 6.

Conversely, it was found that capsules affected positively the self-healing capability of the asphalt mixture increasing in all the amounts studied the maximum healing level value, which happened at $96 \mathrm{~h}$. Once the maximum healing level was reached, it remained constant. This increase in the healing level reached by the mixtures with capsule addition of $0.5 \%$, $0.75 \%$ and $1.00 \%$ was of $100.9 \%, 121.3 \%$ and $126.3 \%$, respectively. Nevertheless, as shown in Table 3, a higher addition of capsules does not necessarily mean improved performance, because a higher number of capsules can also affect their spatial distribution inside the mixture.

\section{Conclusions}

This paper shows results about the effect of encapsulated sunflower oil on the density, air void content, indirect tensile strength, average loss resistance, fatigue performance, and healing properties of dense-graded asphalt mixtures. Based on the results, the following conclusions have been obtained:

- It was proven that Ca-alginate capsules, can affect the bulk density and air void content of asphalt mixtures. The reason for this may be the oil lost by the capsules during asphalt mixing and compaction and the spherical shape of the capsules. Nevertheless, it was observed that $0.5 \%$ of capsule content does not noticeably reduce these properties on the evaluated mixtures.

- The Ca-alginate capsule addition has an influence on the mechanical properties of the dense asphalt mixture. It was found that $0.5 \%$ of capsules is the optimal content for asphalt mixture to obtain good mechanical properties. Compared to plain asphalt mixture without capsules, the mixture containing $0.5 \%$ of capsules has enhanced the indirect tensile strengt, fatigue life and maintained the same particle loss resistance. Note that the air void content of the mixture was affected by the addition of capsules, and that may have had an influence on the results.

- On the contrary, asphalt mixtures with capsule contents of $0.75 \%$ and $1.00 \%$ presented a negative effect on the indirect tensile strength, fatigue, and particle loss properties of the tested specimens. The negative effect was attributed to the capsule size, since they act as soft aggregates into the bituminous matrix.

- CT-Scan results proved that Ca-alginate capsules can survive the mixing and compaction process of asphalt mixture and they will release the oil inside the asphalt by the effect of external compression loading. Higher capsule amounts added in the asphalt mixture resulted in higher oil release ratios. In addition, CT-Scan results also proved that the 
capsules were fixed in the asphalt structure showing a strong adhesion to asphalt mastic by effect of a good interlocking with aggregates.

- The oil released from the Ca-alginate capsules significantly increases the self-healing capability of the dense graded asphalt mixtures, increasing their healing level with all the capsule contents studied until a maximum healing level value, reached after $96 \mathrm{~h}$ of healing. Once the maximum healing level was reached, the healing level of the mixtures remained constant. This was because a new state of physical equilibrium was attained at the crack surface.

- It was proven that higher capsule amounts added in the asphalt mixture resulted in higher healing levels, because a greater amount of rejuvenator is released in the asphalt. However, $0.5 \%$ of capsule addition can be considered as the optimal percentage for asphalt self-healing without affecting the rheological properties of the mixtures.

Acknowledgements The authors express their gratitude for the funding given by Highways England UK, through the Research Project 558065, and to the Royal Society-Newton Mobility Grant, IE150750. The first author thanks the Government of Chile, since his Postdoctoral scholarship was funded by CONICYT/BECAS CHILE 74170030. Additionally, the fifth author thanks the financial support given by the Scientific and Technological Research Council of Turkey (TUBITAK) (application no. 1059B141600780) for the research scholarship granted.

\section{Compliance with ethical standards}

Conflict of interest The authors declare that they have no conflicts of interest.

Open Access This article is distributed under the terms of the Creative Commons Attribution 4.0 International License (http:// creativecommons.org/licenses/by/4.0/), which permits unrestricted use, distribution, and reproduction in any medium, provided you give appropriate credit to the original author(s) and the source, provide a link to the Creative Commons license, and indicate if changes were made.

\section{References}

1. Wu S, Zhao Z, Xiao Y, Yi M, Chen Z, Li M (2017) Evaluation of mechanical properties and aging index of 10-year field aged asphalt materials. Constr Build Mater 155:1158-1167
2. Liu Q, Garcia A, Schlangen E, De Ven MV (2011) Induction healing of asphalt mastic and porous asphalt concrete. Constr Build Mater 25(9):3746-3752

3. García Á (2012) Self-healing of open cracks in asphalt mastic. Fuel 93(1):264-272

4. Liu Q, Schlangen E, Ven MVD, Bochove GV, Montfort JV (2012) Evaluation of the induction healing effect of porous asphalt concrete through four point bending fatigue test. Constr Build Mater 29(4):403-409

5. Su J, Wang Y, Yang P, Han S, Han N, Li W (2016) Evaluating and modeling the internal diffusion behaviors of microencapsulated rejuvenator in aged bitumen by FTIRATR tests. Materials 9(11):932

6. Norambuena-Contreras J, Garcia A (2016) Self-healing of asphalt mixture by microwave and induction heating. Mater Des 106:404-414

7. Grossegguer D, Garcia A (2019) Influence of the thermal expansion of bitumen on asphalt self-healing. Appl Therm Eng 156:23-33

8. Su J, Schlangen E, Wang Y (2015) Investigation the selfhealing mechanism of aged bitumen using microcapsules containing rejuvenator. Constr Build Mater 85:49-56

9. Garcia A, Austin CJ, Jelfs J (2016) Mechanical properties of asphalt mixture containing sunflower oil capsules. J Clean Prod 118:124-132

10. Su JF, Schlangen E (2012) Synthesis and physicochemical properties of high compact microcapsules containing rejuvenator applied in asphalt. Chem Eng J 198-199:289-300

11. Garcia A, Schlangen E, De Ven MV (2011) Properties of capsules containing rejuvenators for their use in asphalt concrete. Fuel 90(2):583-591

12. Su JF, Wang YY, Han NX, Yang P, Han S (2016) Experimental investigation and mechanism analysis of novel multi-self-healing behaviors of bitumen using microcapsules containing rejuvenator. Constr Build Mater 106:317-329

13. Tabaković A, Post W, Cantero D, Copuroglu O, Garcia SJ, Schlangen E (2016) The reinforcement and healing of asphalt mastic mixtures by rejuvenator encapsulation in alginate compartmented fibres. Smart Mater Struct 25(8):084003

14. Micaelo R, Al-Mansoori T, Garcia A (2016) Study of the mechanical properties and self-healing ability of asphalt mixture containing calcium-alginate capsules. Constr Build Mater 123:734-744

15. Al-Mansoori T, Micaelo R, Artamendi I, NorambuenaContreras J, Garcia A (2017) Microcapsules for self-healing of asphalt mixture without compromising mechanical performance. Constr Build Mater 155:1091-1100

16. Al-Mansoori T, Norambuena-Contreras J, Micaelo R, Garcia A (2018) Self-healing of asphalt mastic by the action of polymeric capsules containing rejuvenators. Constr Build Mater 161:330-339

17. Al-Mansoori T, Norambuena-Contreras J, Garcia A (2018) Effect of capsule addition and healing temperature on the self-healing potential of asphalt mixtures. Mater Struct 51:53

18. Norambuena-Contreras J, Yalcin E, Garcia A, Al-Mansoori T, Yilmaz M, Hudson-Griffiths R (2018) Effect of mixing and ageing on the mechanical and self-healing properties of 
asphalt mixtures containing polymeric capsules. Constr Build Mater 175:254-266

19. Xu S, Tabaković A, Liu X, Schlangen E (2018) Calcium alginate capsules encapsulating rejuvenator as healing system for asphalt mastic. Constr Build Mater 169:379-387

20. Norambuena-Contreras J, Yalcin E, Hudson-Griffiths R, Garcia A. Mechanical and self-healing properties of Stone Mastic Asphalt containing encapsulated rejuvenators. J Mater Civil Eng. https://doi.org/10.1061/(asce)mt.19435533.0002687

21. BSI, BS EN 12697-5 (2012) Bituminous mixtures, test methods for hot mix asphalt: determination of the maximum density. British Standard Institute (BSI)

22. BSI, BS EN 12697-6 (2012) Bituminous mixtures, test methods for hot mix asphalt: determination of bulk density of bituminous specimens. British Standard Institute (BSI)

23. Liu Q, Li B, Schlangen E, Sun Y, Wu S (2017) Research on the mechanical, thermal, induction heating and healing properties of steel slag/steel fibres composite asphalt mixture. Appl Sci 7:1088

24. Xu S, García A, Su J, Liu Q, Tabaković A, Schlangen E (2018) Self-healing asphalt review: from idea to practice. Adv Mater Interfaces 5(17):art. no. 1800536

25. Liang P, Want H, Chen C, Ge F, Liu D, Li S, Han B, Xiong X, Zhao S (2013) The use of Fourier Transform Infrared Spectroscopy for quantification of adulteration in virgin walnut oil. J Spectrosc. ID 305604

26. Ji J, Yao H, Suo Z, You Z, Li H, Xu S, Sun L (2016) Effectiveness of vegetable oils as rejuvenators for aged asphalt binders. J Mater Civ Eng 29(3):D4016003

Publisher's Note Springer Nature remains neutral with regard to jurisdictional claims in published maps and institutional affiliations. 